\title{
Immersed with Grit: Probing the Mindset of Future Hospitality Professionals
}

\author{
Ashika Miriam Tharakan a, Dr. Kerwin Savio Nigli ${ }^{\text {b }}$, Dr Boopathy $\mathbf{S}^{\mathrm{c}}$ \\ a Student,CHRIST (Deemed to beUniversity), Bengaluru- 560 029, ashika.tharakan@bhm.christuniversity.in \\ ${ }^{\mathbf{b}}$ Head, Department of Hotel Management, CHRIST (Deemed to be University), Bengaluru- 560029. \\ kerwin.nigli@christuniversity.in, \\ ${ }^{c}$ Associate Professor, School of Business and Management, CHRIST(Deemed tobeUniversity), Bengaluru- 560029. \\ boopathy.srihari@christuniversity.in
}

Article History: Received: 11 January 2021; Accepted: 27 February 2021; Published online: 5 April 2021

\begin{abstract}
Studies in the past have aimed to identify several factors that would encourage academic success among students. In recent times, the focus has shifted to understanding the impact or the influence of non-conventional factors such as Grit and Flow on the performance of students. In the current study, We have identified the relationship between the Grit and the get into a state of flow. The sample for this study consisted of 301 college students pursuing their education in hotel management from colleges in and around Bengaluru City. The data was collected through a questionnaire which was circulated through e-mail and social media of students. The scale used to measure Grit was the 10-item Grit Scale by Angela Duckworth and the 14 Items scale by Kazuki Yoshida was used to measure Flow. Statistical methods such as correlation, regression, t-test and ANOVA were applied in this study. Findings of the study indicate that the grit of hospitality students plays a role in their ability to enter into a state of flow.It is more likely for grittier individuals to experience flow. The levels of grit do not vary in terms of Gender, but it does with respect to year of education. The Flow levels vary between men and women, but it does not differ with year of education.
\end{abstract}

Keywords: Grit, Flow, Consistency of Interest, Perseverance of effort, Hospitality Students.

\section{Introduction}

It has been observed, from studies conducted by Duckworth (2017), that individuals who show a deep interest towards pursuing their goals and do so without wavering along the way show characteristics of being gritty. The study conducted by Duckworth (2017), was focused on students pursuing their university-level education. Findings of this study has shown that students have the ability to persevere through difficulties and hence show qualities of grit.

According to Graham and Hanson (2013), a person displaying qualities of a gritty individual, have the tendency to counter difficulties efficiently, modify or alter themselves to fit into current situations and persist towards their set intentions despite any drawbacks. The authors also go on to say that gritty people tend to be more malleable towards varying situations and always look for practical and constructive outputs.

According to Kannangara CS et al., (2018), psychologists primarily focused on the level of intelligence (IQ) of an individual to determine their chances of becoming successful. However, recent studied by researchers like Duckworth et al. (2007), shows that participants who did not have very high levels of IQ had equal chances of achieving success, which contradicts the studies of early researchers. Many more such studies brought about a change in the attention of psychologists to pay more attention to non-cognitive traits such as determination, concentration, effort, and other attributes that enables people to achieve success.

Grit is a fairly new concept that has become of interest to many researchers and this concept of grit was explored by Angela Duckworth in depth through several studies. Duckworth et al. (2007), paints the concept of grit as the ability to consider their progress and their goals as a long-term effort rather that a short-term temporary task. Prior to studies on non-cognitive traits, the field of education focused on academic achievements as a measure to predict success. Studies on Flow and Grit will enable these institutions to change their perspective and turn their attention towards attributes such as grit and flow which influences the success of a student.

Grit is a non-cognitive construct and has been said to have several positive outcomes. Some of the positive outcomes includes the well-being of an individual their levels of productivity, the educational excellence, contentment and effeciency (Disabato et al., 2018). Grit has been popularized to be considered as a positive trait that stimulates success. It requires one to show signs of self-motivation, engrossment and stive towards achieving goals.

Previous studies have come to the conclusion that grit is related to gender, wherein females have the tendency to be grittier than males (Jaeger et al., 2010; Aswini and Amrita, 2017). Studies have also shown its close relation with age (Cupitt and Golshan, 2015).

Grit is said to play a role when it comes to achieving success in the academic field. Studies by Hodge et al. (2017) shows an increase in students being able to be fruitful and participative in academics. Gritty students are said to show signs of self-stimulation, accomplishment, determination, etc.

When it comes to the completion of a particular job or task, the role of grit is very prominent. Since grit is very much related to determination and engagement, it enables a person to use all their attributes while being aware of 
the stressful or challenging situation that they are facing (Duckworth et al., 2007). Having this quality of grit will enable the person to commit themselves fully towards the task or job at hand and consciously motivate themselves to achieve their targets and complete the task successfully.

Researchers in the past have acknowledged the fact that grit, just like other forms of intelligence is very essential in order to achieve success. People with high levels of grit tend to be infatuated about an idea or task, pay close attention to their task and meticulously finish their task.

Evidence from previous studies show a clear indication of grit being linked to having positive outcomes on individuals, both on a personal as well as professional front. However, there are some studies that go on to explain that levels of grit alone may not be sufficient to predict success (Crede et al., 2016).

Around 40 years ago, the term flow was coined by Csikszentmihalyi (1974). Since then, several studies and research works have been conducted on the topic to understand that flow brings about positive and creative emotions among artists, musicians, sports persons, creative producers, etc. and can be very beneficial to them. Students are no different. Each student possesses skills in various activities and may experience the feeling of being in the 'Zone' where time seems to fly by without them realizing and they feel a sense of accomplishment and joy from the task that they had been doing.

According to Csikszentmihalyi (1974), when an individual engages in a task and when he is fully focused on the task, submerged with ideas, concentration, participation and satisfaction, he is said to have entered into a trancelike state which is coined as flow. When a person experiences flow, they are said to experience and optimal sense of overwhelming state of excitement, thrill, joy and overall receive immense pleasure from doing the task. A person may enter into a state of flow when their entire body and their thoughts are engaged in a challenging or motivating task. Findings of several studies conducted on flow show that people reveal that they are able to find joy on completing a challenging task (Huan Baum,2018).

In order for students to get into the state where they are able to experience flow, they need to be engaged in a task that motivates, excites and challenges them (Csikszentmihalyi, 1974). This is what universities need to consider while developing courses for students. They need to consider whether students find the tasks and activities handed to them challenging enough to get completely absorbed and engrossed in it, yet it must not exceed their capacity and capability to the point that they find it impossible to do with the level of skillsets they have nor must they feel like giving up on the tasks since it no longer interests them.

When a person gets into the zone, they tend to lose track of the time, they do not consider sleep or hunger and they are completely immersed in their task. When students perceive the task to be too challenging or too easy to a point where they find it monotonous, they may not be able to experience flow. Hence, it becomes important for colleges and institutions to help students find the right balance between their skills and the level of difficulty of challenge.

When students experience flow, they will find it within themselves to be more motivated towards exploring the subject or the topic on a deeper level. They will find the interest to learn within themselves. Facilitators can tap into this and explore different ways to make the subject or topic more interesting to them. Certain forms of learning such as introduction of games in the modules, encouraging role plays and activities that stimulate the mind will break the monotony of lectures and sessions and encourage students to be more involved in a classroom setting.

The role of a hospitality professional is very demanding and requires a lot of persistence, patience, hard work, dedication and motivation. Not everyone makes it in this industry, keeping in time the rigorous work schedules and long working hours (Hans Otting, 2013). But those who persist and keep going, see the fruits of their hard work. Customer service involves hard work and dedication in order to achieve customer satisfaction. This is where gritty individuals have an upper hand. Hence it is safe to say that qualities such as Flow and Grit is very essential for hospitality students, and institutions must look into tapping and developing these skills.

In this research paper, we have highlighted our knowledge on grit and flow based on previous literature on these two variables. We have selected students from universities and colleges to participate in this quantitative study, to understand their resilience and whether there is some relevance of their grit to flow.

\section{Review of Literature}

\section{Flow}

Flow is a psychological phenomenon that originated from motivation theory and has been recently brought into the limelight and several studies have been conducted and various models have been proposed. One is said to be in a state of Flow when then have at most concentration and are fully immersed and are able to bring out their best capacities. Some of the positive outcomes of flow include increased levels of achievement, imagination and originality which brings out a sense of satisfaction. (Csikszentmihalyi, 1997).

Flow is commonly perceived as an experience that is undergone by human beings. When a person gets a sense of control of their activities, they tend to be contented with their actions and this motivated them to do more of what brings them joy and happiness. While in the state of Flow, people tend to be aware of their actions as well which gives them a control over what they are doing (Csikszentmihalyi, 1997). 
When a person has entered into a state of flow, they divert their attention wholly onto the task at hand. They are aware of their responsibilities towards accomplishing tasks and the outcomes of completing the task. They often tend to lose track of time when they are in a flow of doing a task (Csikszentmihalyi, 1982). The experience of flow brings about an internal state of calmness and a sense of accomplishment. Flow brings out the ability of a person to face challenges but at the same time balance their skillsets. They tend to get over the initial hesitation and uneasiness of doing a particular task.

According to Walker (2010), a person who can enter into a state of flow can be very beneficial to any organization. Since flow encourages and brings about intrinsic motivation, employers can look at tapping into this to motivate their employees. In order to motivate the employees of an organization to show commitment in performing tasks, flow can be looked as an intrinsic motivator since the employees feel a sense of satisfaction and fulfillment. (Csikszentmihalyi, 1975).To achieve Flow, there must be a balance between the intensity of challenge in the task at hand and the level of skill possessed to engage in that particular task.

In order for a person to show higher levels of productivity they need to be contented with their workplace and the tasks that they are involved in. In case the employees are dissatisfied, they fail to show concentration and commitment to their work (Seligman,2011). Studies conducted by Barrick \& Mound (2005) show that flow can be related to understanding the personality of an individual and can determine if they have the ability to be selfdriven towards achieving tasks.

Kasekende, (2018), studied the mediating influence of flow between self-driven personality and happiness of individuals working in an organization. According to Csikszentmihalyi (2000), some people have the tendency to experience flow more than others. This study looks into whether self-driven people have that ability to be able to experience flow more thanthe others. Being self- driven also brings about satisfaction and happiness amongst employees (Csikszentmihalyi, 1997).

Seligman \&Csikszentmihalyi (2000), observed that when an individual is experiencing flow, the task that they are working on is done without any anticipation of benefits or rewards in the future since they find the activity itself to be a rewarding process. The entire study is based on the hypothesis that flow has a mediating effect between self-driven personality and workplace happiness or satisfaction.

In order to measure the flow experience, authors usework related flow experience inventory which was given by Csikszentmihalyi (2005). The sub scales include challenge and skill balance, concentration on the given task and perceived control.

Milija Šimleša (2018) explained the flow engine framework. Flow brings about the ability to absorb the experience of being fully immersed in a task or activity, the motivation to achieve something out of the task or activity and the feeling of satisfaction and happiness from engaging in the task.

The more frequent a person is able to enter into a state of flow, the more superior would be his standard of life. He would be more attentive and engrossed in the task. He becomes more innovative with his idea and work and would be influenced by positive thoughts (Nakamura \& Csikszentmihalyi, 2002).

Fredrickson \&Losada (2005), studied the various benefits of flow which includes happiness, gratification, satisfaction and fulfillment which is all intrinsic. These optimistic feelings will re-orient the mentality and overall outlook of people. It increases a person's attention span, expand their behavioral patterns and enables them to be more creative (Fredrickson \& Branigan, 2005).

\section{Grit}

Grit has two components, namely, consistency in interests of long-term goals and persistence in pursuing those goals (Duckworth et al., 2007). Several studies in the past such as those of Duckworth et al. (2007), have suggested that psychological factors play an important role in the education sector. Factors such as grit and Flow have been identified to be predictors of academic as well as overall success. When it comes to the completion of a particular job or task, the role of grit is very prominent.

Since grit is very much related to determination and engagement, it enables a person to use all their attributes while being aware of the stressful or challenging situation that they are facing (Duckworth et al., 2007). Having this quality of grit will enable the person to commit themselves fully towards the task or job at hand and consciously motivate themselves to achieve their targets and complete the task successfully.

Suzuki et al. (2015), studied the relationship between grit and work engagement since grit was considered as an indicator of successful work performance. Grit is known as the perseverance that one has to pursue his goal and the consistency of interest on that said goal as stated by Duckworth et al. (2007). From previously conducted studied it is understood that one of the key factors for success is IQ and general mental ability. Another factor is conscientiousness, which is one of the big five personality traits. Grit did not show positive relation with IQ, but it does corelate with the big five personality traits.

Adding to this, Duckworth (2016), says that gritty individuals have a positive outlook towards accomplishing their tasks as well as consider challenges as a stepping stone or as a window of opportunities to develop and better themselves and this tends to show positive results in their work. Grit is applicable to the actions and the way of thinking of people in an institution, whether it is an educational or organizational institute. Since people 
who have grit are able to deal with conflicts arising from goal attainment, companies and organizations look into it as a factor for hiring their employees.

Studies conducted by Duckworth (2007), is able to show a link between grit and academic achievement of undergraduate students. She elaborates that it is essential for students to be resilient in order to draw themselves nearer to success. Self-control enables one to be aware of their behavior and actions despite the presence of distractions. (Duckworth, 2007).

Hodge et al. (2017), examined the role of grit in achieving academic outcomes among university students. Studies conducted by Duckworth (2007) suggest that grit plays an important role in achieving academic excellence. The role of engagement was also examined in the relationship between grit and academic outcomes. Duckworth (2007) captured the concept of grit and identified it as a personality characteristic. The two elements of grit are the consistency in interest to attain a certain long-term goal and the persistence in achieving that goal. According to Hodge et al. (2017), resilience is considered as a driving factor in achieving success. Lufi et al. (1987) defines persistence as the ability to pursue a difficult task. It is alternatively called pursual. This study examined grit in accordance with grades as well as engagement. The hypothesis made was that grit and productivity showed positive association. It was also assumed that grittier students would be more engaged in their studies. The grit scale developed by Duckworth (2009), was used to measure grit. Results showed than males and females did not show differences when it comes to level of grit but students who were the first in the family to attend university showed higher levels of grit. It was observed that interest and effort played a significant role in engagement while both grit and engagement lead to productivity. It was also observed that grit had associations with productivity. Students with high scores on the effort component of grit tend to be more productive.

According to Duckworth (2007), grittier people have the ability to stay committed to long-term work goals and are generally self- motivated and pursue their goals with determination. People who have grit tend to use their time and resources available to stay focused. Duckworth (2016) says that grittier people have a positive outlook towards work and see challenges as opportunities to grow. Grit is a trait that can evolve and develop with time and practice. It leads to the overall happiness and well-being of an individual. A combination of our purpose along with skillsets will fuel us to propel towards our passion.

Theoretical framework

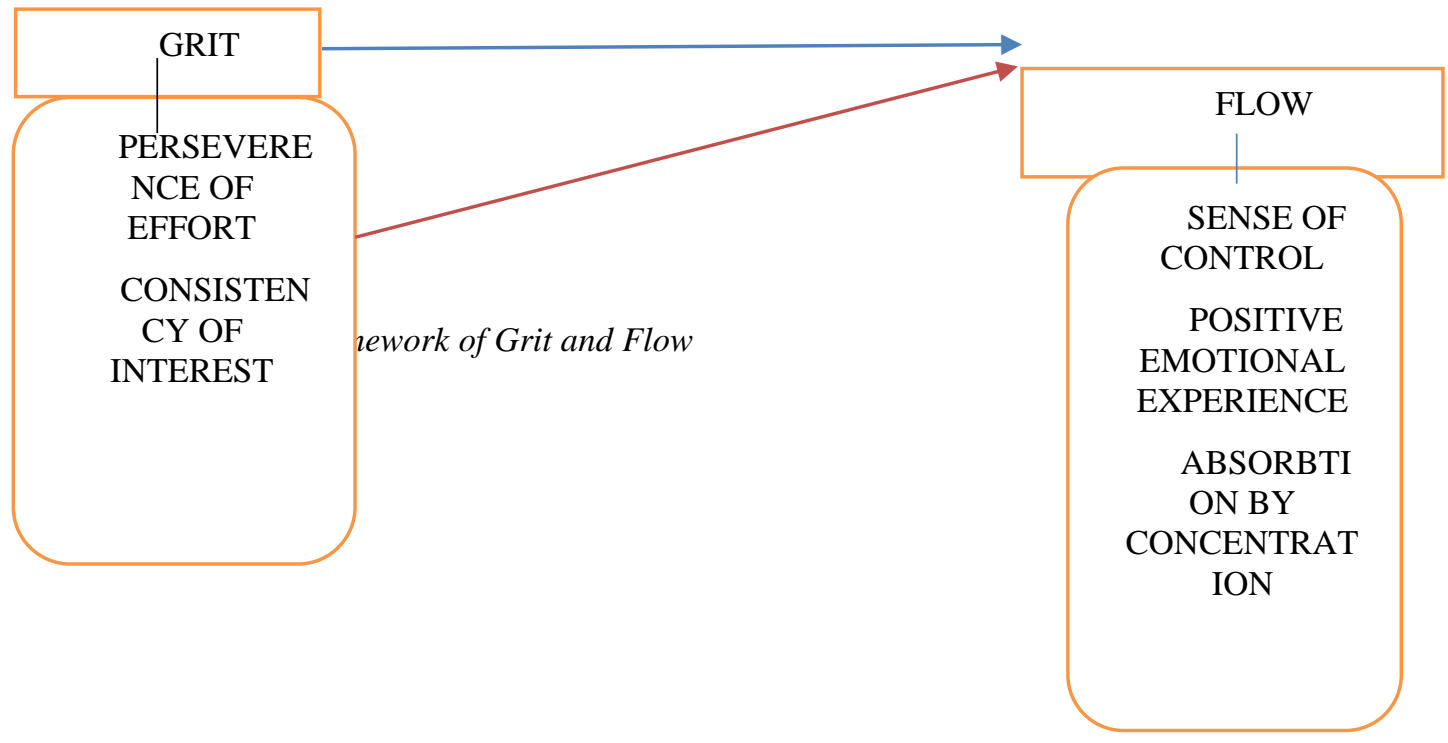

The hospitality industry is one that requires a lot of persistence and commitment. It takes time to grow up the ladder and the job roles are very demanding. In order to reach heights, one has to be extremely focused and have their eyes on the prize. Success comes with a lot of perseverance, dedication, commitment and sacrifice. In order to push through such situations, the students need to have grit and flow to endure the process. There is substantial literature when it comes to the variables, independently, in relation to the hospitality industry or hospitality students in particular. However, no literature has been found to connect their influence to hospitality students. This is the major problem which was identified in this paper.

Significance

This study tries to identify the influence of Grit on the Flow of hospitality students. On having an understanding of how these variables are linked to each other and finding out whether Grittier people have the ability to enter into a state of flow, causes one to gauge their area of development. This paper adds on to the previous studies conducted by other researchers on Grit, Flow and Social Intelligence. It contributes to the studies that connect these variables and brings out the importance of them on hospitality students. 


\section{Scope}

This research paper explores the role of Flow and Grit and their impact on hospitality students. The target population for this research paper was students pursuing their degree in hotel management and hospitality studies. Due to the time constraint, the scope of the population was restricted to students from educational institutions in and around Bengaluru. The scope of this study was limited to students pursuing hotel management and geographical limitations was restricted to institutes in and around Bengaluru.

Objectives

The objectives of this study can be noted down as:

1. To investigate the relationship between Grit and flow amongst hospitality students.

2. To determine whetherdemographic variables such as gender and year of education have an influence on Hypotheses the Flow of hospitality students.

H1: There is a significant relationship between grit and flow amongst hospitality students.

H2:There is a significant difference among respondents with respect to grit based on their gender and year of education.

\section{Research Design}

The current research is descriptive in nature which aimed at addressing the research gap, problem identified and research questions. The paper used a descriptive survey method, where data was collected using questionnaire as the research instrument and this was the primary source of data for this study. Secondary data was collected from research articles sourced from online journals and the theoretical framework as well as research gap was identified from the secondary data. Using statistical methods to analyse the data to test the hypothesis, this research used quantitative data.

\section{Instruments}

The instrument used to measure grit was the 10- item grit scale by Angela Duckworth (2009) of University of Pennsylvania. In order to measure flow, the 14-item scale given by Kazuki Yoshida (2013) was used.

\section{Sample population and size}

The targeted population for the current research study was students pursuing their education and undergraduate degree in hotel management and hospitality studies from educational institutions in and around Bengaluru city. The sample consists of students from all years. Larger sample sizes are always preferred to get more accurate answers. The sample size of this research study was 301 participants.

\section{Reliability and validity}

In order to test the reliability and validity of the scales used in the study and the data that was gathered, a pilot test was conducted. To carry out the pilot test, data was collected randomly from 30 participants. With the help of SPSS (version 21) software, Cronbach's alpha value was calculated for each of the variables to test the reliability of the scales.

\begin{tabular}{|l|l|l|}
\hline Construct & No. of Items & Cronbach Alpha \\
\hline Grit & 10 & 0.811 \\
\hline Flow & 10 & 0.811 \\
\hline
\end{tabular}

Table 1- Reliability statistics of construct

\section{Results:}

The data was computed with the help of SPSS (Version 21) software. A sample of 301 students were included in this research, of which 187 were males and 114 were females. Age-wise, 121 were 20 years or below and 180 were 21-30 years old. 66 students were in the first year, 48 in the second year, 83 in the third year and 101 in the fourth year. 179 had Internship and 122 did not have. In terms of specialization, 118 were in Kitchen \& Bakery, 87 in Front office, 44 in House Keeping and 52 in F\&B.

\section{Cross tabulation comparing YoE and Gender}

\begin{tabular}{|c|c|c|c|c|c|}
\hline \multicolumn{6}{|c|}{ Crosstab } \\
\hline & & & \multicolumn{2}{|c|}{ Gender } & \multirow[b]{2}{*}{ Total } \\
\hline & & & male & female & \\
\hline \multirow[t]{4}{*}{ YoE } & \multirow[t]{2}{*}{ first year } & Number of Respondent & 36 & 30 & 66 \\
\hline & & $\%$ of Gender & $19.5 \%$ & $26.5 \%$ & $22.1 \%$ \\
\hline & \multirow[t]{2}{*}{ second year } & Number of Respondent & 31 & 17 & 48 \\
\hline & & $\%$ of Gender & $16.8 \%$ & $15.0 \%$ & $16.1 \%$ \\
\hline
\end{tabular}




\begin{tabular}{|l|l|l|l|l|l|}
\hline \multirow{3}{*}{} & \multirow{2}{*}{ third year } & Number of Respondent & 50 & 33 & 83 \\
\cline { 3 - 6 } & \multirow{2}{*}{ fourth year } & Number of Respondent & $27.0 \%$ & $29.2 \%$ & $27.9 \%$ \\
\cline { 3 - 6 } & \% of Gender & 68 & 33 & 101 \\
\hline \multirow{2}{*}{ Total } & Number of Respondent & $36.8 \%$ & $29.2 \%$ & $33.9 \%$ \\
\cline { 2 - 5 } & \multicolumn{2}{|l|}{$\%$ of Gender } & 113 & 298 \\
\hline
\end{tabular}

Table 2:Distribution of sample according to year of education and gender

In order to find results for the first objective of this study, which was to examine if there was a relationship between grit and flow of hospitality students, a Pearson's correlation test was done. Results from the test show that the correlation value between grit and flow was found to be 0.022 , which tells us that the value is statistically significant and hence we can accept the alternate hypothesis.

\section{Correlations}

\begin{tabular}{|l|l|l|}
\hline & Grit & Flow \\
\hline Grit & 1 & .022 \\
\hline Flow & & 1 \\
\hline
\end{tabular}

Table 3: Correlation between Grit and Flow.

Similarly, Pearson's correlation was applied within the dimensions of Grit and Flow to examine

\begin{tabular}{|l|l|l|l|l|l|}
\hline Correlations & CI & PoE & SoC & PEE & AbC \\
\hline CI & 1 & $.219^{* *}$ & .027 & $-.163^{* *}$ & $-.269^{* *}$ \\
\hline PoE & & 1 & $.266^{* *}$ & .031 & -.021 \\
\hline SoC & & & 1 & $.434^{* *}$ & $.610^{* *}$ \\
\hline PEE & & & & 1 & $.528^{* *}$ \\
\hline AbC & & & & & 1 \\
\hline$* *$. Correlation is significant at the 0.01 level (2-tailed). \\
\hline
\end{tabular}

Table 4: Pearson's correlation among dimensions of Grit and Flow.

Further on doing a regression test, both the dimensions of the independent variable- Consistency of Interest and Perseverance of Effort have values less than 0.05, which means that they are statistically significant and we can accept the alternate hypothesis. This means, an increase in the independent variable, Grit, will cause an increase in the levels of flow in the students.

\begin{tabular}{|l|l|l|l|l|l|l|}
\hline \multirow{2}{*}{ Model } & \multicolumn{2}{|l|}{ Unstandardized Coefficients } & $\begin{array}{l}\text { Standardized } \\
\text { Coefficients }\end{array}$ & $\mathrm{t}$ & Sig. & $\begin{array}{l}\text { Hypothesi } \\
\text { s } \\
\text { Result } \\
\text { (Alternate) }\end{array}$ \\
\cline { 2 - 7 } & $\mathrm{B}$ & Std. Error & Beta & & & \\
\hline (Constant) & 3.804 & .176 & & 21.560 & .000 & \\
\hline CI & -.099 & .039 & -.147 & -2.529 & .012 & Accepted \\
\hline PoE & .130 & .042 & .181 & 3.099 & .002 & Accepted \\
\hline a. Dependent Variable: F
\end{tabular}

Table 5: Regression between dimensions of Grit and the dependent variable, Flow.

In order to test the second objective, a factorial ANOVA test was done. The tables below describe the total number of males, females and the number of students in each year with respect to Grit and Flow. It also gives the standard deviation and mean values.

\section{Descriptive Statistics}

Dependent Variable: Grit

\begin{tabular}{|l|l|l|l|l|}
\hline Gender & YoE & Mean & Std. Deviation & N \\
\hline \multirow{4}{*}{ male } & first year & 3.4889 & .68192 & 36 \\
\cline { 2 - 5 } & second year & 3.3400 & .61398 & 30 \\
\cline { 2 - 5 } & third year & 3.1980 & .55321 & 49 \\
\cline { 2 - 5 } & fourth year & 3.4660 & .55617 & 68 \\
\hline
\end{tabular}




\begin{tabular}{|l|l|l|l|l|}
\hline \multirow{5}{*}{ female } & Total & 3.3781 & .59864 & 183 \\
\hline \multirow{5}{*}{ Total } & first year & 3.2963 & .77189 & 30 \\
\cline { 2 - 5 } & second year & 3.3412 & .63053 & 17 \\
\cline { 2 - 5 } & third year & 3.1879 & .68773 & 33 \\
\cline { 2 - 5 } & fourth year & 3.5000 & .67222 & 33 \\
\cline { 2 - 5 } & Total & 3.3309 & .70007 & 113 \\
\hline \multirow{5}{*}{} & first year & 3.4013 & .72495 & 66 \\
\cline { 2 - 5 } & second year & 3.3404 & .61314 & 47 \\
\cline { 2 - 5 } & third year & 3.1939 & .60682 & 82 \\
\cline { 2 - 5 } & fourth year & 3.4771 & .59338 & 296 \\
\cline { 2 - 5 } & Total & 3.3601 & .63851 & 101 \\
\hline
\end{tabular}

Descriptive Statistics

Table 6: Demographic mean and standard deviation with respect to Grit.

Dependent Variable: FLOW

\begin{tabular}{|c|c|c|c|c|}
\hline Gender & YoE & Mean & Std. Deviation & $\mathbf{N}$ \\
\hline \multirow{5}{*}{ male } & first year & 4.0516 & .46058 & 36 \\
\hline & second year & 3.9857 & .64638 & 30 \\
\hline & third year & 4.1268 & .50175 & 49 \\
\hline & fourth year & 4.0975 & .47771 & 68 \\
\hline & Total & 4.0780 & .51000 & 183 \\
\hline \multirow{5}{*}{ female } & first year & 3.8476 & .50568 & 30 \\
\hline & second year & 3.9160 & .45051 & 17 \\
\hline & third year & 3.9018 & .64876 & 33 \\
\hline & fourth year & 3.7987 & .77333 & 33 \\
\hline & Total & 3.8594 & .62327 & 113 \\
\hline \multirow{5}{*}{ Total } & first year & 3.9589 & .48866 & 66 \\
\hline & second year & 3.9605 & .57891 & 47 \\
\hline & third year & 4.0363 & .57254 & 82 \\
\hline & fourth year & 3.9999 & .60342 & 101 \\
\hline & Total & 3.9946 & .56504 & 296 \\
\hline
\end{tabular}

Table 7: Demographic mean and standard deviation with respect to Flow.

There is a significant difference in terms of year of education as the value was found to be 0.031 . Which means Grit differs with year of education. There is no difference in the levels of grit in terms of Gender. On combining year of education and gender, once again there is no difference identified.

\begin{tabular}{|c|c|c|c|c|c|}
\hline \multicolumn{6}{|c|}{ Factorial ANOVA Comparing Gender \&YoE with Grit } \\
\hline \multicolumn{6}{|c|}{ Dependent Variable: Grit } \\
\hline Source & $\begin{array}{l}\text { Type III Sum of } \\
\text { Squares }\end{array}$ & & Mean Square & $\mathbf{F}$ & Sig. \\
\hline Corrected Model & $4.413^{\mathrm{a}}$ & 7 & 630 & 1.567 & .145 \\
\hline Intercept & 2888.558 & 1 & 2888.558 & 7180.433 & .000 \\
\hline Gender & .113 & 1 & .113 & .280 & .597 \\
\hline
\end{tabular}




\begin{tabular}{|l|l|l|l|l|l|}
\hline YoE & 3.629 & 3 & 1.210 & 3.007 & .031 \\
\hline Gender * YoE & .538 & 3 & .179 & .446 & .720 \\
\hline Error & 115.857 & 288 & .402 & & \\
\hline Total & 3462.111 & 296 & & & \\
\hline Corrected Total & 120.270 & 295 & & & \\
\hline a. R Squared $=.037$ (Adjusted R Squared $=.013)$ \\
\hline
\end{tabular}

Table 8: Factorial ANOVA Comparing Gender \&YoE with Grit.

On conducting a post-hoc test, it is observed that there is a difference in the levels of grit only when it comes to third- and fourth-year students.

\begin{tabular}{|c|c|c|c|c|c|c|}
\hline \multicolumn{7}{|c|}{ Multiple Comparisons - Post-Hoc Test } \\
\hline \multicolumn{7}{|c|}{$\begin{array}{l}\text { Dependent Variable: Grit } \\
\text { Tukev HSD }\end{array}$} \\
\hline \multirow[t]{2}{*}{ (I) YoE } & \multirow{2}{*}{ (J) YoE } & \multirow{2}{*}{\begin{tabular}{l|} 
Mean \\
Difference (I-J)
\end{tabular}} & \multirow{2}{*}{ Std. Error } & \multirow{2}{*}{ Sig. } & \multicolumn{2}{|c|}{ 95\% Confidence Interval } \\
\hline & & & & & Lower Bound & Upper Bound \\
\hline \multirow{3}{*}{ first year } & second year & .0609 & .12055 & .958 & -.2506 & .3724 \\
\hline & third year & .2074 & .10445 & .196 & -.0624 & .4773 \\
\hline & fourth year & -.0758 & .09997 & .873 & -.3341 & .1825 \\
\hline \multirow{3}{*}{ second year } & first year & -.0609 & .12055 & .958 & -.3724 & .2506 \\
\hline & third year & .1465 & .11556 & .584 & -.1521 & .4451 \\
\hline & fourth year & -.1367 & .11153 & .611 & -.4249 & .1515 \\
\hline \multirow{3}{*}{ third year } & first year & -.2074 & .10445 & .196 & -.4773 & .0624 \\
\hline & second year & -.1465 & .11556 & .584 & -.4451 & .1521 \\
\hline & fourth year & $-.2832^{*}$ & .09389 & .015 & -.5258 & -.0406 \\
\hline \multirow{3}{*}{ fourth year } & first year & .0758 & .09997 & .873 & -.1825 & .3341 \\
\hline & second year & .1367 & .11153 & .611 & -.1515 & .4249 \\
\hline & third year & $.2832^{*}$ & .09389 & .015 & .0406 & .5258 \\
\hline
\end{tabular}

Table 9: Post-hoc test for year of education with respect to Grit.

The table below shows a significant in Gender with respect to flow with a value of 0.05 , which means to say that there is a difference between males and females when it comes to flow. The value for year of education with respect to flow was 0.858 which is well above 0.05 which tells us that there is no difference when it comes to year of education. On combining both year of education and gender, there is no difference.

\section{Tests of Between-Subjects Effects}

Dependent Variable: Flow

\begin{tabular}{|l|l|l|l|l|l|}
\hline Source & $\begin{array}{l}\text { Type III Sum of } \\
\text { Squares }\end{array}$ & df & Mean Square & F & Sig. \\
\hline Corrected Model & $4.000^{\mathrm{a}}$ & 7 & .571 & 1.825 & .082 \\
\hline Intercept & 4042.443 & 1 & 4042.443 & 12909.418 & .000 \\
\hline Gender & 2.555 & 1 & 2.555 & 8.159 & .005 \\
\hline YoE & .239 & 3 & .080 & .255 & .858 \\
\hline Gender * YoE & .388 & 3 & .129 & .413 & .744 \\
\hline Error & 90.184 & 288 & .313 & & \\
\hline Total & 4817.314 & 296 & & & \\
\hline Corrected Total & 94.184 & 295 & & & \\
\hline a. R Squ & & & & \\
\hline
\end{tabular}

a. R Squared $=.042$ (Adjusted R Squared $=.019)$

Discussions

Table 10: Factorial ANOVA Comparing Gender \&YoE with Flow. 
The current research study was carried out in order to understand if there is any relationship between the levels of Grit and Flow of hospitality students. This study was carried out on 301 students pursuing their degree in hotel management from colleges in Bangalore by answering a qualitative questionnaire. From the findings of the study, we were able to arrive at certain conclusions that targets the objective of this study.

Results show that the Pearson's correlation value is statistically significant. This means that there is a relationship between Grit and Flow. Further, on doing a test of regression it was identified that the when the level of Grit of students increase, there is an increase in their ability to get into a state of flow. This means the grittier individuals have higher chances of entering into a state of flow. These findings are in line with the work of Dickinson (2020). From his study he brings out that a person will be able to enter into a state of flow only when the task is challenging and not monotonous. He mentions that Grit will enable a person to push through the challenging task or activity.

Another finding of this study is on demographic variables of Gender and year of education on the Grit and Flow of students. Findings show that there is no difference in the levels of Grit when it comes to males and females. This comes in line with studies of Duckworth (2009), which identified that both males and females are equally gritty. On the other hand, it was also identified that the levels of grit change with the year of education. There was a difference found in the levels of grit among third- and fourth-year students.

When it comes to the Flow of students, results of the study shows that there is a significant difference between the ability of males and females to get into the state of flow. This is consistent with the study of Bryce \& Haworth (2010) where they say that while entering into a state of flow, there will be differences seen in males and females. However, there is no difference between the year of education of students.

From the results we can conclude that a gritty student, through his diligence and passion, will be able to withstand challenges and develop his abilities to cope with the challenge, and as a result is continuously upskilling himself. Hence each time he increases his skillsets, he will be able to enter into a state of flow. When being in a state of flow, he is also more likely to involve himself in the task with consistency. In turn, being in a state of flow will result in the individual receiving a sense of accomplishment and satisfaction that will act as a motivator to push himself to achieve his long-term goals.

\section{Scope for future studies}

Although the current research paper focused on the two variables and their relationship with each other, there is further scope in exploring the implications of the sub-dimensions of Grit and Flow on each other. Avenues such as impact of Grit and Flow on socio-demographic factors can also be explored. This study was conducted only on hospitality students, but similar studies can be conducted on students pursuing different courses or people from other professions as well. The current study was limited to colleges in Bangalore, but future study could cover other geographical areas.

\section{Conclusions}

Both Grit and Flow have the tendency to motivate people to push towards their long/short term goals in pursuit of success and often people no not consider external challenges and distractions while pursuing their goals or tasks. They bring about several positive notions into life such as commitment, purpose and accomplishment. This is very important, especially when it comes to students in order to achieve excellence and success both academically and in extra curricular activities.

However, different situations will require different cognitive abilities to be applied. Grit and Flow can come to help in certain situations, especially in the hospitality industry. Known for its tedious physical work, it will require someone who is passionate and is ready to upskill their abilities in order to grow themselves and reach greater heights. Grit and Flow are not stagnant and require continuous effort.

\section{References}

1. Angela Lee Duckworth \& Patrick D. Quinn (2009) Development and Validation of the Short Grit Scale (Grit-S), Journal of Personality Assessment, 91:2, 166-174, DOI: 10.1080/00223890802634290

2. Annual Review of Personality and Social Psychology, Vol. 3, ed. L. Wheeler

3. Arslan, Serhat. (2014). The Relationships between Achievement Goal Orientations and Grit. TED EĞíTíM VE BİLIM. 39. 10.15390/EB.2014.2125.

4. Aswini, S., and Amrita, D. (2017). Flourishing among postgraduate students: the role of resilience, meaningfulness and grit. Indian J. Commun. Psychol. 13, 24-37.

5. Barrick, M. R., Mount, M. K. (2005). Yes, personality matters: Moving on to more important matters. Human Performance, 18(4), 341-356. doi: 10.1016/S0001-8791(02)00030-1

6. Casper AM, Eddy SL, Freeman S (2019) True Grit: Passion and persistence make an innovative course design work. PLoSBiol 17(7): e3000359. https://doi.org/10.1371/journal.pbio.3000359

7. Caza, A. and Posner, B.Z. (2019), "How and when does grit influence leaders' behavior?", Leadership \& Organization Development Journal, Vol. 40 No. 1, pp. 124-134. https://doi.org/10.1108/LODJ-06-20180209 
8. Chang, W. (2014). Grit and academic performance: Is being grittier better? Order No. 3681407). Available from ProQuest Central; ProQuest Dissertations \& Theses Global. (1655588316).Retrievedfrom https://lavasalibrary.remotexs.in/docview/1655588316?accountid=38885

9. Crede,M., Tynan, M. C., and Harms, P. D. (2016). Much ado about grit: a meta-analytic synthesis of the grit literature. J. Pers. Soc. Psychol. 113, 492-511. doi: 10.1037/pspp0000102

10. Csikszentmihalyi, M. (1982). "Towards a psychology of optimal experience," inCsikszentmihalyi, M. (2000). Happiness, flow, and economic equality. The American Psychologist, 55(10), 11631164.doi:10.1037/0003-066X.55.10.1163

Csikszentmihalyi, Mihaly (1975) Beyond Boredom and Anxiety. San Francisco: Jossey-Bass Publishers.

11. Cupitt, C., and Golshan, N. (2015). Participation in higher education online: demographics, motivators, and grit. Paper Presented at the STARS Conference 2015, Melbourne, VIC. Available at: http://www.unistars.org/papers/STARS2015/09C.pdf

12. Dickinson, Samuel (2020) "Grit and Flow as Prescriptions for Self-Actualization," Journal of Wellness. Doi: https://ir.library.louisville.edu/jwellness/vol2/iss2/4

13. Disabato, David \& Goodman, Fallon \&Kashdan, Todd. (2018). Is grit relevant to well-being and strengths? Evidence across the globe for separating perseverance of effort and consistency of interests. Journal of Personality. 87. 10.1111/jopy.12382.

14. Duckworth, A. (2016). Grit: The power of passion and perseverance. Scribner/Simon \& Schuster.

15. Duckworth, A. (2017). Grit: The Power of Passion and Perseverance. London: Vermilion.

16. Dugan, Riley \& Hochstein, Bryan \&Rouziou, Maria \& Britton, Benjamin. (2018). Gritting their Teeth to Close the Sale FORTHCOMING JPSSM. Journal of Personal Selling and Sales Management.

17. Francis, Kasekende. (2018). Self-driven personality and happiness at the workplace: The mediation role of Flow Experience", Journal of Organizational Psychology.

18. Fredrickson, B. L., \& Branigan, C. A. (2005). Positive emotions broaden the scope of attention and thought-action repertoires. Cognition and Emotion, 19, 313-332. doi:10.1080/02699930441000238

19. Fredrickson, B. L., \&Losada, M. F. (2005). Positive affect and the complex dynamics of human flourishing. The American Psychologist, 60(7), 678-686. doi:10.1037/0003-066X.60.7.678

20. Graham, L., and Hanson, R. (2013). Bouncing Back: Rewiring your Brain for Maximum Resilience and Well-Being. Novato, CA: New World Library.

21. Hagger, Martin \& Hamilton, Kyra. (2018). Grit and Self-Discipline as Predictors of Effort and Academic Attainment. British Journal of Educational Psychology. 89. 10.1111/bjep.12241.

22. Hans Otting (2013) Hospitality management students' cognitive style, Research in Hospitality Management, 3:1, 33-38, DOI: 10.1080/22243534.2013.11828301

23. Hodge, B., Wright, B., and Bennett, P. (2017). The role of grit in determining engagement and academic outcomes for university students. Res. Higher Educ. 59:448. doi: 10.1007/s11162-017-9474-y

24. Huan Baum, W. Y. (2018). The Optimal Experience: Achieving Organizational Flow. Journal of Advanced Research in English and Education , 3(3), 31-37.

25. Jaeger, B., Freeman, S., Whalen, R., and Payne, R. (2010). Successful students: smart or tough? Paper Presented at 2010 Annual Conference and Exposition: Research on the First Year, American Society of Engineering Education, Louisville, KY

26. Kumar, A., Kumar, P., Srivastava, A., Kumar, V., Vengatesan, K., \& Singhal, A. (2020). Comparative Analysis of Data Mining Techniques to Predict Heart Disease for Diabetic Patients. In International Conference on Advances in Computing and Data Sciences (pp. 507-518).

27. Jo Bryce \& John Haworth (2002) Wellbeing and flow in sample of male and female office workers, Leisure Studies, 21:3-4, 249-263, DOI: 10.1080/0261436021000030687

28. Jordan, Mark \& Gabriel, T.J. \& Teasley, Russell \& Walker, Wendy \&Schraeder, Mike. (2015). An integrative approach to identifying factors related to long-term career commitments: A military example. Career Development International. 20. 163-178. 10.1108/CDI-05-2013-0071.

29. Jordan, S.L., Hochwarter, W.A., Ferris, G.R. and Ejaz, A. (2018), "Work grit as a moderator of politics perceptions: Workplace outcomes relationships: a three-study convergent investigation", Career Development International, Vol. 23 No. 6/7, pp. 576-594. https://doi.org/10.1108/CDI-09-2018-0247

30. JunbangLan, C.-S. W. (2017). The effect of leadership on work-related flow: a moderated mediation model. Leadership \& Organization, 38(2), 210-228. doi:10.1108/LODJ-08-2015-0180

31. Kannangara CS, Allen RE, Waugh G, Nahar N, Khan SZN, Rogerson S and Carson J (2018) All That Glitters Is Not Grit: Three Studies of Grit in University Students. Front. Psychol. 9:1539. doi: 10.3389/fpsyg.2018.01539

32. Lufi, Dubi\& Cohen, Arie. (1987). A Scale for Measuring Persistence in Children. Journal of personality assessment. 51. 178-85. 10.1207/s15327752jpa5102_2.

33. Marino Bonaiuto, Y. M. (2016). Optimal Experience and Personal Growth: Flow and the Consolidation of Place Identity. Front. Psychol., 7(1654). doi:10.3389/fpsyg.2016.01654 
34. Mark Kasa, Z. H. (2020). ROLE OF FLOW BETWEEN JOB DEMAND AND JOB. International Journal of Business and Society, 21(1), 168-182.

35. Maurer, Mia \&Daukantaitè, Daiva. (2015). Grit and Different Aspects of Well-Being: Direct and Indirect Relationships via Sense of Coherence and Authenticity. Journal of Happiness Studies. 10.1007/s10902015-9688-7. Musumari PM, Tangmunkongvorakul A,

36. MilijaŠimleša, J. G. (2018). The Flow Engine Framework: A Cognitive Model of Optimal Human. Europe's Journal of Psychology, 14(1), 232-253. doi:10.5964/ejop.v14i1.1370

37. Nakamura, J., \& Csikszentmihalyi, M. (2002). The concept of flow. In C. R. Snyder \& S. J. Lopez (Eds.), Handbook of positive psychology (pp. 89-105). New York, NY, USA: Oxford University Press.

Pate, A. N., Payakachat, N., Harrell, T. K., Pate, K. A., Caldwell, D. J., \& Franks, A. M. (2017). Measurement of Grit and Correlation to Student Pharmacist Academic Performance. American journal of pharmaceutical education, 81(6), 105. https://doi.org/10.5688/ajpe816105

38. Rafael A. B. Tedesqui\& Bradley W. Young (2017) Investigating grit variables and their relations with practice and skill groups in developing sport experts, High Ability Studies, 28:2, 167-180, DOI: 10.1080/13598139.2017.1340262

39. RITA P. DE DEVOTTO, C. P. (2020). THE ROLE OF JOB CRAFTING ON THE PROMOTION OF FLOW AND WELLBEING. Revista de Administração Mackenzie, 21(1), 1-24. doi:10.1590/16786971/eRAMD200113

40. Robert S. Weisskirch (2019) Grit Applied Within: Identity and Well-being, Identity, 19:2, 98-108, DOI: 10.1080/15283488.2019.1604345

41. Salisu, I., Hashim, N., Mashi, M.S. and Aliyu, H.G. (2020), "Perseverance of effort and consistency of interest for entrepreneurial career success: Does resilience matter?", Journal of Entrepreneurship in Emerging Economies, Vol. 12 No. 2, pp. 279-304. https://doi.org/10.1108/JEEE-02-2019-0025

42. Seligman, M. E. P. (2011). Flourish a visionary new understanding of happiness and well-being. New York, NY: Free Press.

43. Shenkle, N. M. (2018). An analysis of grit scores on first-year undergraduate students' persistence at a large private university (Order No. 10929770). Available from ProQuest Central; ProQuest Dissertations $\begin{array}{lllll}\text { \& Theses (2116579846). Global. } & \text { Retrieved }\end{array}$ https://lavasalibrary.remotexs.in/docview/2116579846?accountid=38885

44. Suzuki Y, Tamesue D, Asahi K, Ishikawa Y (2015) Grit and Work Engagement: A Cross-sectional Study. PLoS ONE 10(9): e0137501. doi:10.1371/journal.pone.0137501

45. Suzuki, Y., Tamesue, D., Asahi, K., \& Ishikawa, Y. (2015). Grit and work engagement: A crosssectional study. PLoS One, 10, e0137501 https://doi.org/10.1371/journal.pone.0137501

46. Walker, C. J. (2010). Experiencing flow: Is doing it together better than doing it alone? The Journal of Positive Psychology. 